\title{
MicroRNA profiling of benign and malignant pheochromocytomas identifies novel diagnostic and therapeutic targets
}

Goswin Y Meyer-Rochow ${ }^{1,5,6 *}$, Nicole E Jackson ${ }^{1,5 *}$, John V Conaglen ${ }^{7}$, Denis E Whittle ${ }^{6}$, Muthusamy Kunnimalaiyaan ${ }^{8}$, Herbert Chen ${ }^{8}$, Gunnar Westin ${ }^{9}$, Johanna Sandgren ${ }^{9}$, Peter Stålberg ${ }^{9}$ Elham Khanafshar ${ }^{10}$, Daniel Shibru ${ }^{10}$, Quan-Yang Duh ${ }^{10}$, Orlo H Clark ${ }^{10}$, Electron Kebebew ${ }^{11}$ ', Anthony J Gill, ${ }^{4}$, Rory Clifton-Bligh ${ }^{1,3,5}$, Bruce G Robinson ${ }^{1,3,5}$, Diana E Benn ${ }^{1,5,+}$ and Stan B Sidhu ${ }^{1,2,5, t}$

\footnotetext{
${ }^{1}$ Cancer Genetics, Hormones and Cancer Group, Kolling Institute of Medical Research, Departments of ${ }^{2}$ Endocrine and Oncology Surgery, ${ }^{3}$ Endocrinology and ${ }^{4}$ Anatomical Pathology, Royal North Shore Hospital, St Leonards, Sydney, New South Wales 2065, Australia

${ }^{5}$ Faculty of Medicine, The University of Sydney, Sydney, New South Wales 2006, Australia

Departments of ${ }^{6}$ Surgery and ${ }^{7}$ Endocrinology, Faculty of Medical and Health Sciences, Waikato Clinical School,

University of Auckland, Auckland 1142, New Zealand

${ }^{8}$ Endocrine Surgery Research Laboratories, Department of Surgery, The University of Wisconsin (UW), and UW Carbone Cancer Centre, Madison, Wisconsin 1142, USA

${ }^{9}$ Department of Surgical Sciences, University Hospital, Uppsala SE-751 85, Sweden

${ }^{10}$ Departments of Surgery and Pathology, University of California at San Francisco, San Francisco, California 93143, USA

${ }^{11}$ Endocrine Oncology Section, Surgery Branch, National Cancer Institute, Bethesda, Maryland 20892-1201, USA
}

(Correspondence should be addressed to S B Sidhu who is now at AMA House, 202/69 Christie Street, St Leonards, New South Wales 2065, Australia; Email: stansidhu@ nebsc.com.au)

*(G Y Meyer-Rochow and N E Jackson contributed equally to this work)

${ }^{\dagger}$ (D E Benn and S B Sidhu contributed equally as senior author of this work)

\begin{abstract}
MicroRNAs (miRNAs) are small RNAs ( $\sim 22 \mathrm{bp})$ that post-transcriptionally regulate protein expression and are found to be differentially expressed in a number of human cancers. There is increasing evidence to suggest that miRNAs could be useful in cancer diagnosis, prognosis, and therapy. We performed miRNA microarray expression profiling on a cohort of 12 benign and 12 malignant pheochromocytomas and identified a number of differentially expressed miRNAs. These results were validated in a separate cohort of ten benign and ten malignant samples using real-time quantitative RT-PCR; benign samples had a minimum follow-up of at least 2 years. It was found that IGF2 as well as its intronic miR-483-5p was over-expressed, while miR-15a and miR-16 were under-expressed in malignant tumours compared with benign tumours. These miRNAs were found to be diagnostic and prognostic markers for malignant pheochromocytoma. The functional role of miR-15a and miR-16 was investigated in vitro in the rat PC12 pheochromocytoma cell line, and these miRNAs were found to regulate cell proliferation via their effect on cyclin D1 and apoptosis. These data indicate that miRNAs play a pivotal role in the biology of malignant pheochromocytoma, and represent an important class of diagnostic and prognostic biomarkers and therapeutic targets warranting further investigation.
\end{abstract}

Endocrine-Related Cancer (2010) 17 835-846

\section{Introduction}

Pheochromocytomas are catecholamine-producing neuroendocrine tumours of chromaffin cell origin arising from the adrenal medulla and less commonly from extra-adrenal sympathetic paraganglia. Approximately $24 \%$ of pheochromocytoma cases are caused 
by germ line mutations in genes associated with multiple endocrine neoplasia type 2, von HippelLindau disease, and the pheochromocytoma/paraganglioma familial syndromes, but the remaining $76 \%$ are sporadic and the pathogenesis remains unknown (Neumann et al. 2002, Adler et al. 2008). Approximately $10 \%$ of pheochromocytoma cases are malignant (DeLellis et al. 2004); however, this malignant potential cannot be determined histologically, and there is currently no diagnostic test that can predict whether a tumour is benign or malignant. A definitive diagnosis of malignancy can therefore only be made after metastasis has occurred (DeLellis et al. 2004). Previously investigated cancer-associated markers such as p53 and $\mathrm{Ki}-67$ and catecholamine-related markers such as chromogranin A are not reliable diagnostic markers of malignant pheochromocytoma (Brouwers et al. 2005, Strong et al. 2008). In addition, patients with malignant pheochromocytoma respond poorly to chemotherapy or radiotherapy with a poor overall survival of $50 \%$ at 5 years (Adler et al. 2008). The identification of reliable diagnostic and prognostic markers and the development of effective molecular therapeutic targets for the treatment of malignant disease have the potential to significantly improve the outcome for patients with malignant pheochromocytoma.

MicroRNAs (miRNAs) are a class of small nonprotein-coding RNAs $(\sim 22 \mathrm{bp})$ that negatively regulate protein expression. These single stranded RNA fragments have hundreds of predicted targets and act by binding to the $3^{\prime}$ untranslated region (UTR) of the mRNA, leading to either mRNA cleavage or translational repression (Engels \& Hutvagner 2006). The first study implicating miRNAs in the development of cancer came from the observation that the most common deletions in human chronic lymphocytic leukaemia (CLL) occur in the 13q14 chromosomal region (Calin et al. 2002). Two miRNAs (miR-15 and miR-16) are located in this region and have been found to be deleted or down-regulated in $\sim 68 \%$ of all cases of CLL (Calin et al. 2002). Down-regulation of miR-15a and miR-16 has also been reported in pituitary adenomas, prostate cancer, and non-small cell lung cancer (Bottoni et al. 2005, Cimmino et al. 2005, Bonci et al. 2008, Bandi et al. 2009).

MiRNA expression is tissue specific and has been demonstrated to be altered in a number of human cancers including colon (Bandres et al. 2006), prostate (Porkka et al. 2007, Bonci et al. 2008), lung (Takamizawa et al. 2004, Yanaihara et al. 2006), thyroid (He et al. 2005, Pallante et al. 2006, Weber et al. 2006), hepatocellular (Murakami et al. 2006,
Huang et al. 2008, Li et al. 2008, Wang et al. 2008, Wong et al. 2008), pancreas (Roldo et al. 2006, Bloomston et al. 2007, Lee et al. 2007, Szafranska et al. 2007), brain (Bottoni et al. 2005, Ciafre et al. 2005), ovarian (Iorio et al. 2007, Dahiya et al. 2008, Nam et al. 2008, Yang et al. 2008), and cervical (Lui et al. 2007, Lee et al. 2008) cancers. However, miRNA expression in pheochromocytoma has not been reported.

Here, we report the results of miRNA microarray expression profiling of a large cohort of benign and malignant pheochromocytoma tumours where we identified a number of differentially expressed miRNAs. These differences in expression were validated in a separate cohort of benign and malignant pheochromocytoma samples using real-time quantitative RT-PCR (qPCR). The functional role of miR-15a and miR-16 was also investigated using the rat PC12 malignant pheochromocytoma cell line, in which these miRNAs were shown to regulate proliferation and apoptosis.

\section{Materials and methods}

\section{Definitions}

Pheochromocytoma (adrenal or extra-adrenal) catecholamine-producing tumours of chromaffin cell origin; benign pheochromocytoma - solitary chromaffin tumour with no evidence of metastasis with at least 2 years of follow-up after resection; malignant pheochromocytoma - chromaffin tumour with metastasis to a region where chromaffin tissue would not be expected either at initial presentation or during follow-up (DeLellis et al. 2004); sporadic pheochromocytoma - tumour where no familial history of pheochromocytoma or syndrome-related tumours were present, and/or no germ line mutations were identified. Locally invasive or recurrent tumours were not considered malignant and were excluded from the benign sample cohort in this study in order to avoid ambiguity.

\section{Pheochromocytoma and normal control tissue samples}

Ethical approval for the collection of tissue from patients and clinical data were obtained from the Northern Sydney Area Health Ethics Committee and from participating Institutional Human Research Ethics Committees. Tissue samples were obtained at the time of surgery, snap frozen in liquid nitrogen and stored at $-80^{\circ} \mathrm{C}$. MiRNA microarray expression profiling was carried out using a primary cohort of 12 benign and 12 malignant tumours, and five normal 
adrenal medulla tissue samples were used as a normal reference (internal cohort). Of the malignant tumours in the internal cohort, ten were primary tumours and two were metastases from a primary tumour in that cohort. An independent cohort of ten benign and ten primary malignant tumours (external cohort) was used to validate the miRNA microarray results using qPCR. Clinical details of patients in the internal cohort and external cohort are given in Supplementary Tables 1 and 2, see section on supplementary data given at the end of this article. Normal adrenal medulla was sourced from uninvolved adrenal gland adjacent to a small $(<4 \mathrm{~cm})$ non-functioning adrenocortical incidentaloma or small aldosterone-producing adenoma (Conn's syndrome). Tumour specimens and normal medulla were examined histologically and confirmed to contain at least $80 \%$ tumour cells or adrenal medulla before being used in the study. Germ line mutations were analysed using dHPLC as described previously (Meyer-Rochow et al. 2009), and any variants were sequenced.

\section{RNA extraction}

Total RNA was extracted from fresh-frozen tissue $(50 \mathrm{mg})$ of normal adrenal medulla, pheochromocytoma, or the rat PC12 cell line (passage 17) using TRIzol reagent (Invitrogen) according to the manufacturer's protocol. RNA was further purified by precipitation with $7.5 \mathrm{M}$ lithium chloride (Ambion Inc., Austin, TX, USA) according to the manufacturer's protocol and stored at $-80{ }^{\circ} \mathrm{C}$. RNA concentration and purity were measured by u.v. absorbance at 260/280 nm (Nanodrop ND-1000; Nanodrop Technologies, Wilmington, DE, USA), and quality was assessed using the Agilent Bioanalyser 2100 (Agilent Technologies, Inc., Santa Clara, CA, USA).

\section{MiRNA microarray profiling}

MiRNA microarray profiling was performed by Exiqon Services (Vedbaek, Denmark) using miRCURY LNA Arrays. All the RNA tumour samples met the minimum quality criteria for miRNA microarray analysis requested by Exiqon $(260 / 280 \mathrm{~nm}$ ratios $>1.7$, $260 / 230 \mathrm{~nm}$ ratios $>1.4$ and a RNA integrity number >7.0). One hundred nanograms of total RNA from each sample and reference (pooled RNA of all samples) were labelled with $\mathrm{Hy} 3$ and Hy5 fluorescent labels respectively using the miRCURY LNA Array power labelling kit (Exiqon) following the procedure described by the manufacturer. The Hy3-labelled samples and a Hy5-labelled reference RNA sample were mixed pairwise and hybridised to the miRCURY LNA array version 11.0 (Exiqon), which contains capture probes targeting all miRNAs for human, mouse or rat registered in the miRBase version 13.0 at the Sanger Institute. The hybridisation was performed according to the miRCURY LNA array manual using a Tecan HS4800 hybridisation station (Tecan, Grodig, Austria). After hybridisation, the microarray slides were scanned and stored in an ozone-free environment (ozone level below $2.0 \mathrm{ppb}$ ) in order to prevent potential bleaching of the fluorescent dyes. The miRCURY LNA array microarray slides were scanned using the Agilent G2565BA Microarray Scanner System (Agilent Technologies, Inc.), and the image analysis was carried out using the ImaGene 8.0 software (BioDiscovery, Inc., El Segundo, CA, USA). The quantified signals were background corrected (Normexp with offset value 10 (Ritchie et al. 2007)) and normalised using the global LOcally WEighted Scatterplot Smoothing (Lowess) regression algorithm.

\section{MiRNA qPCR analysis}

Differential expression was confirmed in selected miRNAs (miR-15a, miR-16, and miR-483-5p) from total RNA by qPCR using TaqMan miRNA assay probes (Applied Biosystems, Foster City, CA, USA) following the manufacturer's instructions. qPCR was performed on a Corbett Rotor-Gene 3000 (Corbett Research, Mortlake, NSW, Australia) using genespecific TaqMan Gene Expression Assays and TaqMan Universal PCR Master Mix (Applied Biosystems). RNU48 was used as the internal control for normalisation (Applied Biosystems). All the samples were run in triplicate and repeated a minimum of two times. qPCR results were analysed using the relative expression software tool (REST, 2005, Corbett Research, Sydney, NSW, Australia).

\section{Co-expression of insulin-like growth factor 2 with miR-483-5p}

Relative expression of insulin-like growth factor 2 (IGF2) was evaluated by qPCR and immunohistochemistry. Total RNA from each tumour and normal tissue sample was reverse transcribed into cDNA using random hexamers and the Superscript III first-strand synthesis system (Invitrogen). Each PCR was performed as a duplex reaction with the gene-specific FAM-TAMRA-labelled TaqMan probe and a ribosomal 18S RNA VIC-labelled TaqMan probe as the internal control for normalisation (Applied Biosystems). 
Immunohistochemistry was performed on formalin-fixed, paraffin-embedded tissue sectioned at $4 \mu \mathrm{m}$ using a mouse monoclonal anti-IGF2 primary antibody (Clone S1F2; Upstate Cell Signalling Solutions, Lake Placid, NY, USA) at a dilution of 1 in 400. All slides were processed with the Vision Biosystems Bondma X autostainer (Vision Biosystems, Mount Waverley, VIC, Australia) according to the manufacturer's protocol and with the manufacturer's retrieval solutions. Scoring of IGF2 was performed by histological examination and graded semi-quantitatively by a blinded observer from 0 to $4+$.

\section{Survival and receiver operating characteristic analysis in malignant pheochromocytoma}

The ability of IGF2, miR-483-5p, miR-15a, and miR-16 to provide diagnostic and prognostic information for patients with malignant disease was evaluated using follow-up data available from 17 of the 22 patients with malignant disease. Kaplan-Meier survival curves, receiver operating characteristic (ROC) curves, and statistical analysis were performed using SPSS (SPSS v16.0, Chicago, IL, USA). $P<0.05$ was considered significant.

\section{Cell culture}

Rat pheochromocytoma cells (PC12) were obtained from American Tissue Culture Collection (Rockville, MD, USA) and cultured in DMEM supplemented with $10 \% \mathrm{v} / \mathrm{v}$ horse serum (HS) and 5\% v/v fetal bovine serum (FBS) and maintained in a humidified chamber $\left(5 \% \mathrm{CO}_{2}\right.$ and $\left.37^{\circ} \mathrm{C}\right)$. Cells were confirmed mycoplasma free.

\section{MiRNA transfection}

Fifty microlitres of pre-miR hsa-miR-15a, pre-miR hsa-miR-16, or pre-miR-negative control \#1 (premiR-NC1; Ambion) in OptiMEM I (Invitrogen), final concentration of $100 \mathrm{nM}$, were mixed with $50 \mu \mathrm{l}$ of Lipofectamine 2000 (Invitrogen) $(25 \times$ dilution in OptiMEM I) per well, incubated at room temperature for $20 \mathrm{~min}$, then added to each well of a 24-well plate $(100 \mu \mathrm{l})$. PC12 cells $\left(400 \mu \mathrm{l}\right.$ of $6.25 \times 10^{5}$ cells $\left./ \mathrm{ml}\right)$ were subsequently added to each well. The transfection mixture was incubated $\left(5 \% \quad \mathrm{CO}_{2}\right.$ and $\left.37^{\circ} \mathrm{C}\right)$ for $24 \mathrm{~h}$, then either the cells were used immediately in assays or the media was replaced $(500 \mu \mathrm{l}$ DMEM/10\% v/v HS/5\% v/v FBS) and incubated further. To determine the transfection efficiency, Cy3labelled pre-miR-NC1 was transfected into PC12 cells using Lipofectamine as described above, and the cells were analysed using BD FACSCalibur flow cytometer (BD Biosciences, San Jose, CA, USA). The homology between rat and human mature miR-15a or miR-16 is $100 \%$.

\section{Cell cycle and cell death analysis}

Changes in cell cycle and apoptosis in response to premiR treatment were analysed by flow cytometry using propidium iodide (PI) or Annexin V respectively. For cell cycle analysis, cells treated with pre-miR-NC1, pre-miR-15a, or pre-miR-16 were washed with PBS, resuspended in 5\% v/v Triton X-100 $(75 \mu \mathrm{l})$ and RNase was added $(10 \mathrm{mg} / \mathrm{ml}, 25 \mu \mathrm{l})$, followed by the addition of PI $(0.5 \mathrm{mg} / \mathrm{ml}, 25 \mu \mathrm{l}$; Sigma-Aldrich). PBS was then added to a final volume of $250 \mu \mathrm{l}$. Induction of apoptosis was measured using the PE Annexin V apoptosis detection kit I (BD Biosciences) as per the manufacturer's instructions. Cell counts and viability were assessed using trypan blue exclusion.

\section{Western blot analysis}

The effect of pre-miR transfection on protein expression was analysed by western blot. Twenty micrograms of total protein from triplicate samples of pre-miR-NC1-, pre-miR-15a-, or pre-miR-16-treated PC12 cells were separated on a $12 \% \mathrm{v} / \mathrm{v}$ SDS-PAGE gel and transferred onto a nitrocellulose membrane. After blocking overnight at $4{ }^{\circ} \mathrm{C}$ with $5 \%$ w/v skim milk powder $/ 0.1 \%$ v/v Tween 20/Tris-buffered saline (TBS), membranes were incubated with either $1 \mu \mathrm{g} / \mathrm{ml}$ CCND1 (clone DCS-6, BD Biosciences) or $1 \mu \mathrm{g} / \mathrm{ml} \mathrm{BCL2} \mathrm{(clone} \mathrm{7/BCL-2,} \mathrm{BD}$ Biosciences) (5\% w/v skim milk powder/0.1\% v/v Tween 20/TBS, $1 \mathrm{~h}, \mathrm{RT}$ ). Bound primary antibody was detected using a goat anti-mouse HRP-conjugated secondary antibody (Dako, Glostrup, Denmark) diluted $1000 \times(30 \mathrm{~min}, \mathrm{RT})$, followed by exposure to a HRP chemiluminescence substrate for $30 \mathrm{~s}$ (ECL Plus Western Blotting Detection System, GE Healthcare, Chalfont St Giles, UK). The resulting bands were visualised using the LAS 4000 system (FujiFilm, Tokyo, Japan).

\section{Statistical analyses of functional assays}

In cell viability, cell cycle analysis and western blotting assays, statistical significance was determined using an one-way ANOVA, with Tukey's test or Bonferroni's as the post-test; $P<0.05$ was considered significant. Data were collected from three independent experiments performed in triplicate and expressed as the S.E.M. Statistical analyses were performed using GraphPad Prism 5 (GraphPad Software, Inc., La Jolla, CA, USA). 
Table 1 Significantly differentially expressed miRNAs between 12 benign and 12 malignant human pheochromocytoma tumours

\begin{tabular}{|c|c|c|c|c|c|}
\hline \multicolumn{3}{|c|}{$\begin{array}{l}\text { Up-regulated in malignant compared with } \\
\text { benign pheochromocytoma }\end{array}$} & \multicolumn{3}{|c|}{$\begin{array}{l}\text { Down-regulated in malignant compared with } \\
\text { benign pheochromocytoma }\end{array}$} \\
\hline miRNA & $P$ & Fold change & miRNA & $P$ & Fold change \\
\hline hsa-miR-603 & $8.69 \times 10^{-4}$ & +2.3 & hsa-miR-451 & $1.34 \times 10^{-3}$ & -9.0 \\
\hline hsa-miR-483-5p & $9.57 \times 10^{-3}$ & +2.1 & hsa-miR-144 & $1.36 \times 10^{-4}$ & -6.5 \\
\hline hsa-miR-431* & $5.12 \times 10^{-3}$ & +2.0 & hsa-miR-16 & $9.92 \times 10^{-4}$ & -3.4 \\
\hline hsa-miR-138-1* & $1.94 \times 10^{-3}$ & +1.7 & hsa-miR-19b & $9.45 \times 10^{-3}$ & -3.1 \\
\hline hsa-miR-574-3p & $4.07 \times 10^{-3}$ & +1.7 & hsa-miR-15a & $2.89 \times 10^{-4}$ & -3.0 \\
\hline hsa-miR-483-3p & $5.87 \times 10^{-4}$ & +1.6 & hsa-miR-557 & $2.59 \times 10^{-4}$ & -2.6 \\
\hline hsa-miR-877 & $7.61 \times 10^{-3}$ & +1.6 & hsa-miR-33a & $7.85 \times 10^{-3}$ & -2.4 \\
\hline hsa-miR-766 & $7.46 \times 10^{-3}$ & +1.4 & hsa-miR-887 & $5.25 \times 10^{-3}$ & -2.1 \\
\hline miRPlus_42530 & $8.62 \times 10^{-4}$ & +1.3 & miRPlus_28302 & $8.11 \times 10^{-3}$ & -1.3 \\
\hline
\end{tabular}

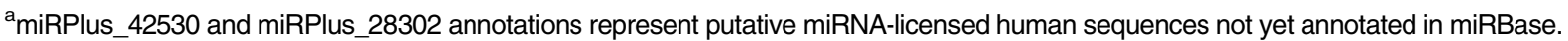

\section{Results}

\section{Comparison of miRNA expression in benign and malignant pheochromocytomas}

MiRNA expression was compared between benign and malignant pheochromocytoma tumours, and a total of 18 miRNAs were identified as being significantly differentially expressed with $P<0.001$ after correction for multiple comparisons (Table 1). The heat map shows a distinct difference between benign and malignant samples which also clustered into two groups (unsupervised hierarchical clustering; Fig. 1). There was good separation between the benign and malignant tumour groups with three exceptions: patient sample 12 which is a benign tumour that clustered with the malignant tumours, and the malignant patient samples 22 and 23, both of which clustered with the benign samples. Unsupervised hierarchical clustering of miRNA expression demonstrated tight clustering of
miRNAs derived from the same stem-loop sequence (miR-483-5p/miR-483-3p) or in close genomic proximity (miR-15a/miR-16 and miR-144/miR-451). These miRNA pairs also showed similar patterns of expression. In a separate analysis, the rat PC12 malignant pheochromocytoma cell line clustered with the group of malignant tumour samples. The normal samples clustered separately from both the benign and malignant samples, with the exception of one benign tumour, patient sample 7, which clustered with the malignant tumours.

\section{Validation of differentially expressed miRNAs in benign and malignant pheochromocytomas}

Three miRNAs (miR-483-5p, miR-15a, and miR-16) were selected for $\mathrm{qPCR}$ validation using the original miRNA microarray cohort (internal) or the external cohort of ten benign and ten malignant tumours.

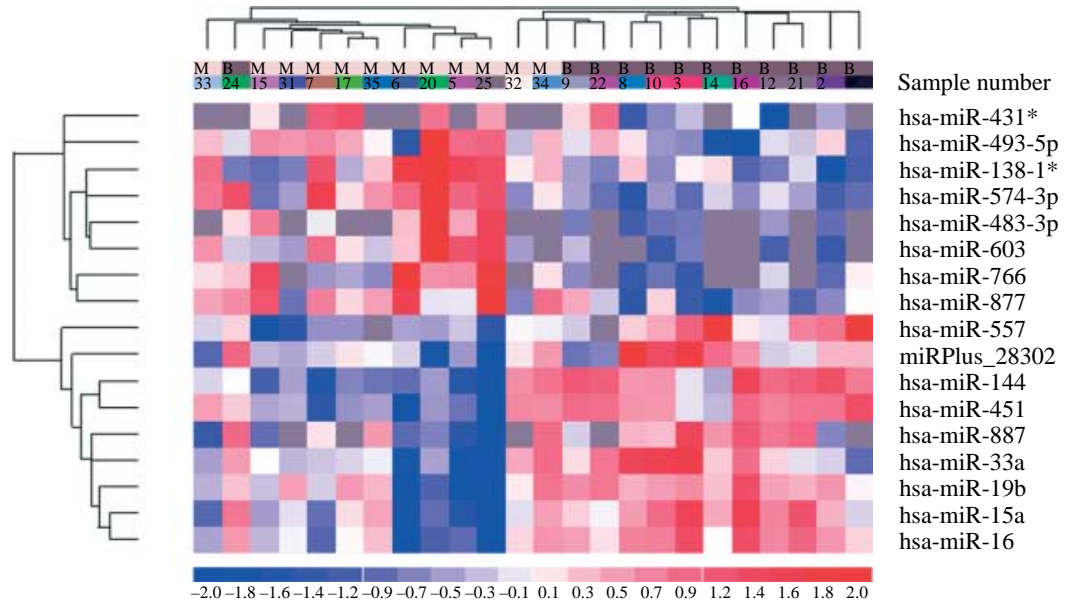

Figure 1 Heat map of differentially expressed miRNAs between 12 benign (B) and 12 malignant (M) pheochromocytoma tissues with unsupervised hierarchical clustering by miRNA and tumour type; red indicates increased expression, and blue indicates decreased expression relative to pooled reference RNA; grey indicates inadequate signal for assessment. 


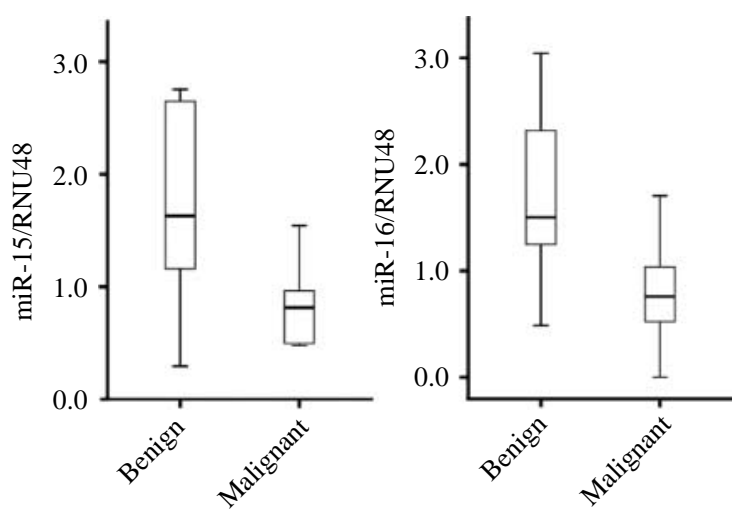

Figure 2 Decreased expression of miR-15a $(A)$ and miR-16 (B) in malignant $(n=10)$ tumours compared with benign $(n=10)$ pheochromocytoma tumours $(P=0.007$ and $P=0.029$ respectively, Mann-Whitney $U$ test).

These miRs were selected on the basis that they have been reported to be involved in the pathogenesis of other cancers, specifically miR-15a and miR-16 have been found to be under-expressed in prostate, lung, and ovarian cancer, and miR-483-5p has been overexpressed in adrenocortical cancer (Bonci et al. 2008, Bandi et al. 2009, Bhattacharya et al. 2009, Soon et al. 2009a). Analysing the external cohort alone, there was a significant reduction in miR-15a and miR-16 expression in malignant tumours compared with benign tumours $(P=0.007$ and $P=0.029$ respectively; Fig. 2). There was also a trend towards increased miR483-5p expression in the malignant tumours in the external cohort alone (data not shown), but this was not statistically significant $(P=0.199)$. However, when quantification of miR-483-5p relative expression was extended to include both internal and external cohorts of benign and malignant tumours, as well as of normal medulla, there was a statistically significant increase in expression in malignant tumours compared with normal medulla $(P<0.01)$ and in malignant tumours compared with benign tumours $(P<0.01$; Fig. 3A).

\section{Co-expression of IGF2 mRNA and miR-483-5p}

The genomic location of miR-483-5p which is within the second intron of IGF 2 at $11 \mathrm{p} 15.5$ suggests a high likelihood of co-expression, which has not previously been reported; however, we have previously observed this in adrenocortical carcinoma (Soon et al. 2009b). To test this hypothesis, we measured IGF2 mRNA expression by qPCR. There was a significant increase in expression of $I G F 2$ in malignant tumours compared with benign tumours $(P<0.01)$ and in malignant tumours compared with normal medulla $(P<0.05$;
Fig. 3B). The relative expression of $I G F 2$ and miR-483-5p were positively correlated (Spearman correlation coefficient of $0.72(P<0.001)$; Fig. 3C). To determine if IGF2 protein expression could be used as a predictor of malignant disease, 15 benign and 10 malignant tissue samples were stained for IGF2 (where tissue was available). There was a statistically significant increase in IGF2 expression in malignant tumours compared with benign tumours $(P=0.001)$. Strong $(3+$ or $4+)$ IGF2 immunohistochemical
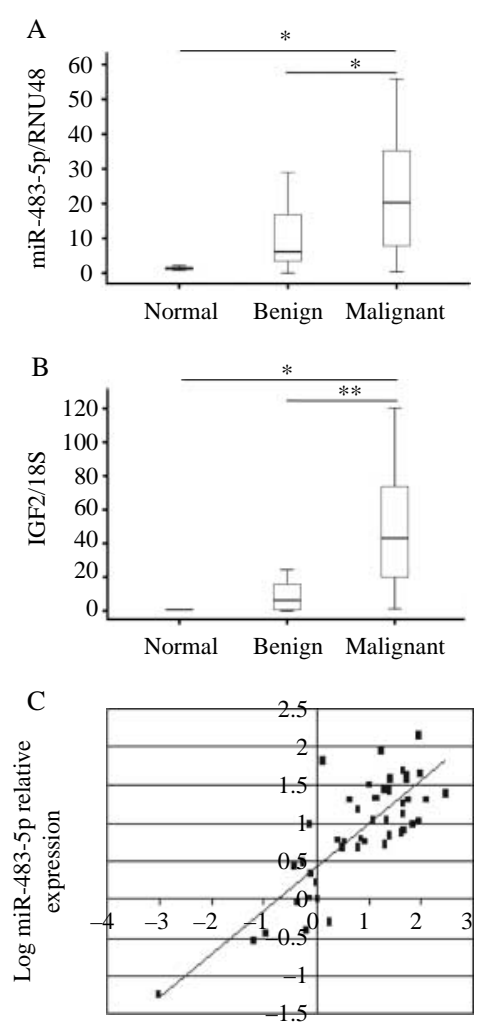

Log IGF2 mRNA relative expression

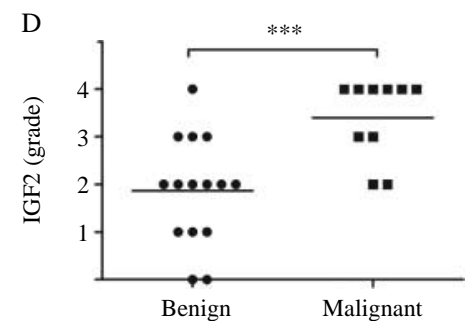

Figure 3 MiR-483-5p and IGF2 mRNA are increased in malignant pheochromocytoma. Relative expression of (A) miR-483-5p and (B) IGF2 mRNA in normal adrenal medulla $(n=5)$ and benign $(n=22)$ and malignant $(n=21)$ pheochromocytomas by qPCR $\left({ }^{\star} P<0.05\right.$ and ${ }^{\star \star} P<0.01$, ANOVA \& Dunn's). (C) Positive correlation between miR-483-5p and IGF2 mRNA (Spearman Correlation, $P<0.001$ ). (D) IGF2 protein is increased in malignant pheochromocytoma compared with benign pheochromocytoma; immunohistochemical grading was performed (Grades $0-4,{ }^{\star \star \star} P=0.001$, Spearman correlation). 

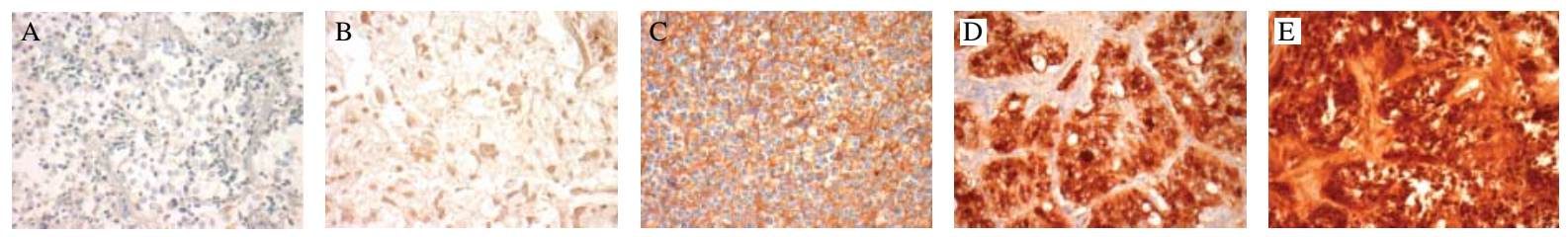

Figure 4 Immunohistochemical staining (IHC) for IGF2. IHC score: 0 - no staining (A), 1 - intra-cytoplasmic specks only (B), 2 - focal peri-nuclear dot-like pattern of staining (C), 3 - peri-nuclear dot-like and homogeneous cytoplasmic staining in some cells only (D), 4 - peri-nuclear dot-like and homogeneous cytoplasmic staining in all or nearly all tumour cells (E).

staining was present in $80 \%$ of the malignant tumours (Fig. 3D) compared with $27 \%$ of the benign tumours. Examples of each category of immunohistochemical grading are shown in Fig. 4.

\section{Clinical utility of miR-483-5p, IGF2, miR-15a, and miR-16 expression in the diagnosis and prognosis of malignant pheochromocytoma}

Disease-free survival and patient survival were compared using Kaplan-Meier analysis according to high or low expression of $I G F 2$, miR-483-5p, miR-15a, or miR-16 in 17/20 patients where outcome data were available using qPCR data. Of these, miR-483-5p was significant for predicting patients who were more likely to have metastatic disease at the time of initial presentation and have worse disease-free survival $(P=0.05)$ but not overall survival (Fig. 5).

To determine if $I G F 2$, miR-483-5p, miR-15a, or miR-16 could be used to differentiate benign from malignant tumours at initial surgical resection, ROC analysis was performed on qPCR data. Both high $I G F 2$ and low miR-15a had an area under the curve value $>0.85$ indicating high diagnostic accuracy

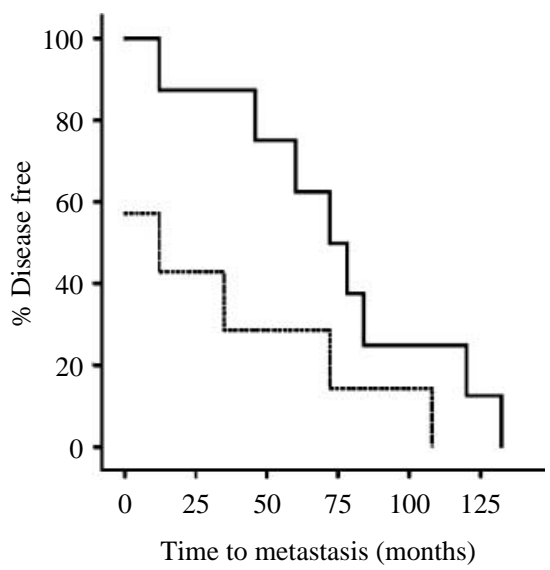

Figure 5 Disease-free survival of patients with malignant pheochromocytoma relative to miR-483-5p expression dichotomised to the median value of the primary malignant samples (log-rank 0.05); solid line indicates high expression, and dotted line indicates low expression.
(IGF2, $P<0.001$ and miR-15a, $P=0.008$ respectively; Supplementary Figure 1, see section on supplementary data given at the end of this article). IGF2 had a sensitivity of $100 \%$ and specificity of $70 \%$, while miR-15a had a sensitivity of $90 \%$ and specificity of $80 \%$. Based on ROC analysis, a cut-off for each was chosen, and the ability of a high IGF2 level and low miR-15a level to distinguish malignant from benign tumours was investigated. The area under the ROC curve for both in combination was $0.9(P=0.002,80 \%$ sensitivity and $100 \%$ specificity), meaning that all of benign tumours were called correctly using this method, and that $20 \%$ of the malignant tumours were identified as benign. In addition, we found that for immunohistochemical staining of $I G F 2$ protein in benign and malignant tumours the area under the curve in ROC analysis was $0.85, P=0.003(80 \%$ sensitive and $73 \%$ specific).

\section{Pre-miR-15a and pre-miR-16 inhibit proliferation and induce cell death in the rat PC12 pheochro- mocytoma cell line}

To determine the functional effect and thus their potential use in therapy, miR-15a and miR-16 were reintroduced as either pre-miR-15a or pre-miR-16 transfection into the rat PC12 malignant cell line. The homology between rat and human mature miR-15a or miR-16 is $100 \%$. Reintroduction of pre-miR-15a or pre-miR-16, compared with the scrambled control premiR-NC1, both led to a decrease in cell viability (Fig. 6A) and cell number (Fig. 6B) as determined by trypan blue exclusion. A significant decrease in viability was observed at $48 \mathrm{~h}$ (pre-miR-15a and premiR-16, $P<0.01$ ) and $72 \mathrm{~h}$ (pre-miR-15a, $P<0.001$ and pre-miR-16, $P<0.01)$, but not at $24 \mathrm{~h}(P>0.05)$ compared with the scrambled control, pre-miR-NC1. Similarly, a significant decrease in cell number was observed at $48 \mathrm{~h}$ (pre-miR-15a and pre-miR-16, $P<0.05)$ and $72 \mathrm{~h}$ (pre-miR-15a and pre-miR-16, $P<0.01)$, but not at $24 \mathrm{~h}(P>0.05)$ compared with the scrambled control, pre-miR-NC1. The transfection efficiency was determined as $91 \%$ using Cy3-labelled 


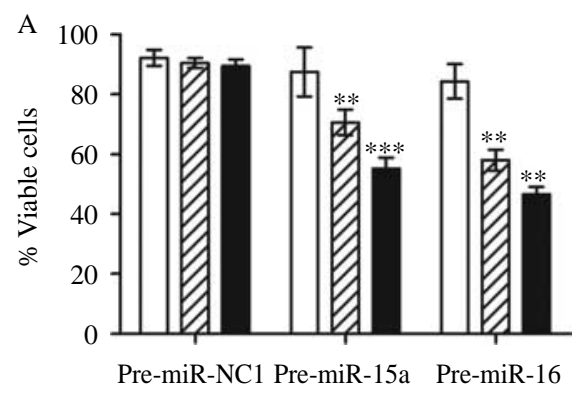

B
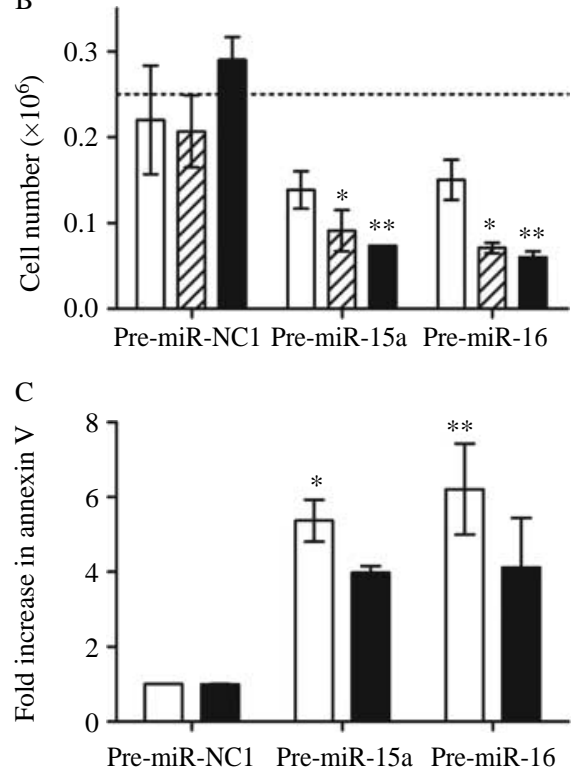

$\mathrm{D}$

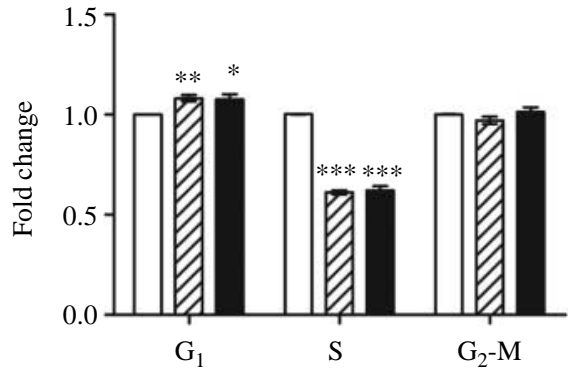

Figure 6 Pre-miR-15a and pre-miR-16 induce cell death and inhibit proliferation in rat PC12 cells. Decrease in cell viability (A), cell number (B), increase in apoptosis by Annexin V staining (C); white bar -24 , hatched bar -48 or black bar $-72 \mathrm{~h}$ post transfection with pre-miR-15a, pre-miR-16, or pre-miR-NC1 scrambled control. (D) Cell cycle analysis by propidium iodide staining; white bar - pre-miR-NC1, hatched bar - pre-miR-15a, and black bar - pre-miR-16. Data are expressed as the mean and S.E.M. of three independent experiments performed in triplicate. Significant decrease in viability is indicated $\left({ }^{\star} P<0.05\right.$ ${ }^{\star \star} P<0.01$ and ${ }^{\star \star \star} P<0.001$, ANOVA \& Tukey's test).

pre-miR-NC1 (Supplementary Figure 2, see section on supplementary data given at the end of this article).

To determine if cell death was due to the induction of apoptosis, Annexin V cell surface expression was investigated. A significant increase in Annexin $\mathrm{V}$ cell surface expression was observed at $48 \mathrm{~h}(P<0.05)$ after transfection with pre-miR-15a or pre-miR-16 compared with the scrambled control, pre-miR-NC1 (Fig. 6C).

To determine if pre-miR-15a or pre-miR-16 transfection of the rat PC12 cell line would affect their proliferation, cell cycle analysis was performed. DNA synthesis was significantly reduced in premiR-15a- and pre-miR-16-transfected cells compared with scrambled control, pre-miR-NC1 (Fig. 6D and Supplementary Figure 3, see section on supplementary data given at the end of this article). In addition, there was a significant increase in the number of cells in the $\mathrm{G}_{1}$ phase of cell cycle, indicating that there is inhibition of the $G_{1}$ to $S$ phase transition.

\section{Pre-miR-15a and pre-miR-16 decrease CCND1 protein expression}

The change in the level of expression of CCND1 (a cell cycle regulatory protein), a known target of miR-15a and miR-16, was analysed by western blotting and densitometry. There was a significant decrease in CCND1 expression in PC12 cells after transfection with pre-miR-15a $(P<0.01)$ or pre-miR-16 $(P<0.05$; Fig. 7A and B). BCL2 was found not to be expressed in PC12 cells by western blotting.

\section{Discussion}

Currently, it is not possible to predict malignancy in patients with pheochromocytoma, and many investigated cancer-related genes have not proven to be reliable diagnostic or prognostic markers (Brouwers et al. 2005, Strong et al. 2008). MiRNAs have been shown to be differentially expressed in tumours compared with normal tissues (Lu et al. 2005), as well as in benign tumours compared with malignant tumours (Schultz et al. 2008, Soon et al. 2009a), and therefore have potential as novel diagnostic and prognostic markers. MiRNAs have also been implicated in tumourigenesis and therefore represent potential therapeutic targets. This is the first report of miRNA expression profiling of a large cohort of benign and malignant pheochromocytomas with the identification of diagnostic and prognostic biomarkers and potential therapeutic targets.

Here we report that 18 miRNAs were found to be differentially expressed between benign and malignant tumours by microarray analysis (Table 1 ). Of these, miR-15a and miR-16 were confirmed to have reduced expression in malignant tumours compared with benign tumours, and miR-483-5p was 


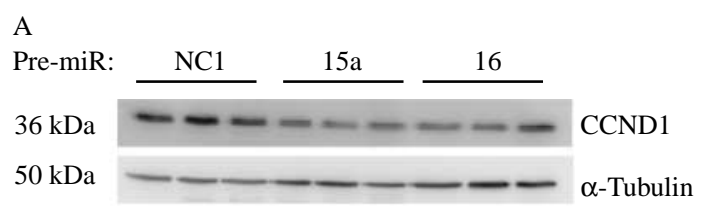

B

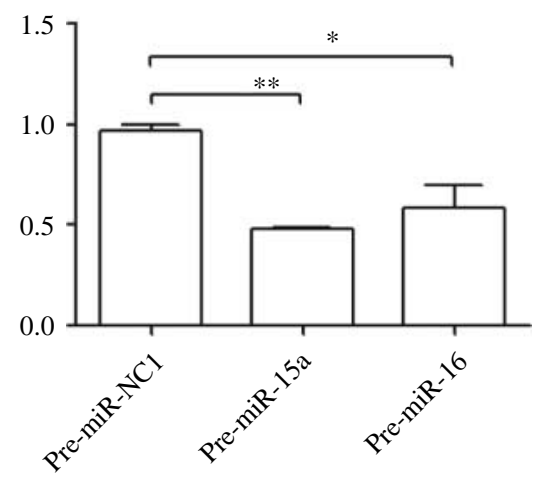

Figure 7 Pre-miR-15a and pre-miR-6 decrease CCND1 protein expression in rat PC12 cells. Western blot analysis of CCND1 (A) protein in PC12 cells $24 \mathrm{~h}$ after transfection with pre-miR$15 a$ or pre-miR-16, relative to pre-miR-NC1scrambled control. Analysis by densitometry (B) showed that this decrease was significant; each lane was normalised using $\alpha$-tubulin and is expressed relative to the scrambled control. Data are expressed as the mean and S.E.M. of three independent experiments performed in triplicate. Significant inhibition is indicated ( ${ }^{\star} P<0.05$ and ${ }^{* \star} P<0.01$, ANOVA \& Tukey's test).

confirmed to have increased expression by qPCR (Figs 2 and 3). Of the three validated miRNAs, miR483-5p appeared to be predictive of metastasis at initial surgery and worse disease-free survival (Fig. 5) but not overall survival.

An increased level of miR-483-5p in malignant tumours was correlated with an increase in $I G F 2$ mRNA (Fig. 3). MiR-483-5p is located at $11 \mathrm{p} 15.5$ within the second intron of $I G F 2$, and here we report its co-expression with $I G F 2$. Therefore, we investigated whether IGF2 could also be used to differentiate benign from malignant tumours. There was a statistically significant increase in both mRNA and protein expression of $I G F 2$ in malignant tumours compared with benign tumours which has not been previously reported in pheochromocytoma. IGF2 protein is known to be increased in a number of tumours including Wilms' tumour (Ravenel et al. 2001) and adrenocortical cancers (Schmitt et al. 2006), and we have previously shown that $I G F 2$ immunohistochemistry can be used to differentiate adrenal cortical adenomas from carcinomas in combination with Ki-67 (Soon et al. 2009a). Moreover, we have also observed that miR-483-5p is up-regulated in adrenocortical carcinoma, which is consistent with our current finding of IGF2 and miR-483-5p co-expression.

We further analysed by ROC analysis whether these three validated differentially expressed miRNAs with the addition of $I G F 2$ mRNA and protein levels could distinguish malignant from benign pheochromocytoma. IGF2 and miR-15a produced an area under the curve value of 0.86 identifying them as having high diagnostic accuracy, i.e. a high level of IGF2 and a low level of miR-15a would be predictive of a malignant tumour. A cut-off for each was then defined based on ROC analysis, and it was found that a high IGF2 level and a low miR-15a level were able to differentiate benign from malignant tumours $(80 \%$ sensitive and $100 \%$ specific). This was confirmed for IGF2 protein by immunohistochemistry, where the area under the curve in ROC analysis was 0.85 (80\% sensitive and $73 \%$ specific). This identifies the combination of IGF2 mRNA/protein and miR-15a expression levels as a potential diagnostic test to differentiate benign from malignant tumours, and would require further validation in a larger cohort.

Reintroduction of miR-15a and miR-16 in the malignant rat PC12 pheochromocytoma cell line was found to induce cell death and inhibit proliferation (Fig. 6) - to date there is no human malignant pheochromocytoma cell line available. This is the first time that this has been reported, and given the high homology between rat and human miRNAs, this suggests that miR-15a and miR-16 may be novel therapeutic targets for treatment of patients with metastatic pheochromocytoma. Previous studies have shown a decreased expression of miR-15a and miR-16 in prostate (Bonci et al. 2008), pituitary (Bottoni et al. 2005), lung (Bandi et al. 2009), and ovarian cancers (Bhattacharya et al. 2009). In addition, reintroduction of miR-15a and miR-16 has been reported to reduce tumour size in a mouse model of prostate cancer (Bonci et al. 2008, Takeshita et al. 2010), providing proof-of-principle for their use as a therapeutic target.

Previous studies have demonstrated that miR-15a and miR-16 regulate CCND1 and BCL2 expression in other cancers (Bonci et al. 2008, Roccaro et al. 2009). We have shown that in a rat malignant pheochromocytoma cell line, restoration of miR-15a and miR-16 results in a decrease in CCND1 (a cell cycle regulator) expression and leads to inhibition of proliferation (Fig. 7). BCL2 was found not to be expressed in the rat PC12 cell line, as has been shown in the literature (Díaz-Prieto et al. 2008), and thus the mechanism of cell death after miR-15a/miR-16 reintroduction warrants further investigation. 
The inability to differentiate benign from malignant pheochromocytoma, as well as the paucity of effective treatments for metastatic disease, highlights the urgent need to identify biomarkers of malignancy and novel therapeutic targets. We report for the first time that several miRNAs are differentially expressed in malignant tumours compared with benign pheochromocytoma tumours. IGF2 and miR-15a have the potential to be utilised as diagnostic markers of malignancy following surgical resection of the primary tumour. MiR-483-5p is a marker of worse disease-free survival in malignant pheochromocytoma. Restoration of miR-15a and miR-16 in a rat cell line of malignant pheochromocytoma has an effect of inducing apoptosis and inhibiting cell proliferation, which can be partially explained via their effect on the known target CCND1. Further work is required to expand the role for these miRNAs as a potential therapeutic intervention.

\section{Supplementary data}

This is linked to the online version of the paper at http://dx. doi.org/10.1677/ERC-10-0142.

\section{Declaration of interest}

The authors declare that there is no conflict of interest that could be perceived as prejudicing the impartiality of the research reported.

\section{Funding}

G Y Meyer-Rochow is a recipient of the National Health and Medical Research Council (NHMRC, Australia) Postgraduate Research Scholarship, the Cancer Institute of New South Wales (CINSW, Australia) Postgraduate Scholarship and the Royal Australasian College of Surgeons (RACS) Surgeon Scientist Scholarships. S B Sidhu is a NSW Cancer Institute Clinical Research Fellow. D E Benn is supported by the Hillcrest Foundation.

\section{References}

Adler JT, Meyer-Rochow GY, Chen H, Benn DE, Robinson BG, Sippel RS \& Sidhu SB 2008 Pheochromocytoma: current approaches and future directions. Oncologist 13 779-793. (doi:10.1634/theoncologist.2008-0043)

Bandi N, Zbinden S, Gugger M, Arnold M, Kocher V, Hasan L, Kappeler A, Brunner T \& Vassella E 2009 miR-15a and miR-16 are implicated in cell cycle regulation in a $\mathrm{Rb}$-dependent manner and are frequently deleted or down-regulated in non-small cell lung cancer. Cancer Research 69 5553-5559. (doi:10.1158/0008-5472. CAN-08-4277)

Bandres E, Cubedo E, Agirre X, Malumbres R, Zarate R, Ramirez N, Abajo A, Navarro A, Moreno I, Monzo M et al. 2006 Identification by real-time PCR of 13 mature microRNAs differentially expressed in colorectal cancer and non-tumoral tissues. Molecular Cancer 5 29. (doi:10. 1186/1476-4598-5-29)

Bhattacharya R, Nicoloso M, Arvizo R, Wang E, Cortez A, Rossi S, Calin GA \& Mukherjee P 2009 MiR-15a and MiR-16 control Bmi-1 expression in ovarian cancer. Cancer Research 69 9090-9095. (doi:10.1158/00085472.CAN-09-2552)

Bloomston M, Frankel WL, Petrocca F, Volinia S, Alder H, Hagan JP, Liu CG, Bhatt D, Taccioli C \& Croce CM 2007 MicroRNA expression patterns to differentiate pancreatic adenocarcinoma from normal pancreas and chronic pancreatitis. Journal of the American Medical Association 297 1901-1908. (doi:10.1001/jama.297.17.1901)

Bonci D, Coppola V, Musumeci M, Addario A, Giuffrida R, Memeo L, D'Urso L, Pagliuca A, Biffoni M, Labbaye C et al. 2008 The miR-15a-miR-16-1 cluster controls prostate cancer by targeting multiple oncogenic activities. Nature Medicine 14 1271-1277. (doi:10.1038/nm.1880)

Bottoni A, Piccin D, Tagliati F, Luchin A, Zatelli MC \& Uberti ECD 2005 miR-15a and miR-16-1 downregulation in pituitary adenomas. Journal of Cellular Physiology 204 280-285. (doi:10.1002/jcp.20282)

Brouwers FM, Petricoin EF III, Ksinantova L, Breza J, Rajapakse V, Ross S, Johann D, Mannelli M, Shulkin BL, Kvetnansky R et al. 2005 Low molecular weight proteomic information distinguishes metastatic from benign pheochromocytoma. Endocrine-Related Cancer 12 263-272. (doi:10.1677/erc.1.00913)

Calin GA, Dumitru CD, Shimizu M, Bichi R, Zupo S, Noch E, Aldler H, Rattan S, Keating M, Rai K et al. 2002 Frequent deletions and down-regulation of micro- RNA genes miR15 and miR16 at 13q14 in chronic lymphocytic leukemia. PNAS 99 15524-15529. (doi:10.1073/pnas.242606799)

Ciafre SA, Galardi S, Mangiola A, Ferracin M, Liu CG, Sabatino G, Negrini M, Maira G, Croce CM \& Farace MG 2005 Extensive modulation of a set of microRNAs in primary glioblastoma. Biochemical and Biophysical Research Communications 334 1351-1358. (doi:10.1016/ j.bbrc.2005.07.030)

Cimmino A, Calin GA, Fabbri M, Iorio MV, Ferracin M, Shimizu M, Wojcik SE, Aqeilan RI, Zupo S, Dono M et al. $2005 \mathrm{miR}-15$ and miR-16 induce apoptosis by targeting BCL2. PNAS 102 13944-13949. (doi:10.1073/ pnas.0506654102)

Dahiya N, Sherman-Baust CA, Wang TL, Davidson B, Shih Ie M, Zhang Y, Wood W III, Becker KG \& Morin PJ 2008 MicroRNA expression and identification of putative miRNA targets in ovarian cancer. PLOS ONE 3 e2436. (doi:10.1371/journal.pone.0002436)

DeLellis R, Lloyd R, Heitz P \& Eng C 2004 Tumours of the adrenal gland. In WHO Classification of Tumours, Pathology and Genetics of Tumours of Endocrinology, edn 1, pp 147-155. Lyon: IARC Press.

Díaz-Prieto N, Herrera-Peco I, de Diego AMG, Ruiz-Nuño A, Gallego-Sandín S, López MG, García AG \& 
Cano-Abad MF 2008 Bcl 2 mitigates $\mathrm{Ca}^{2+}$ entry and mitochondrial $\mathrm{Ca}^{2+}$ overload through downregulation of L-type $\mathrm{Ca}^{2+}$ channels in PC12 cells. Cell Calcium 44 339-352. (doi:10.1016/j.ceca.2008.01.007)

Engels BM \& Hutvagner G 2006 Principles and effects of microRNA-mediated post-transcriptional gene regulation. Oncogene 25 6163-6169. (doi:10.1038/sj.onc.1209909)

He H, Jazdzewski K, Li W, Liyanarachchi S, Nagy R, Volinia S, Calin GA, Liu C-G, Franssila K, Suster S et al. 2005 The role of microRNA genes in papillary thyroid carcinoma. PNAS 102 19075-19080. (doi:10.1073/pnas. 0509603102)

Huang YS, Dai Y, Yu XF, Bao SY, Yin YB, Tang M \& Hu CX 2008 Microarray analysis of microRNA expression in hepatocellular carcinoma and non-tumorous tissues without viral hepatitis. Journal of Gastroenterology and Hepatology 23 87-94. (doi:10.1111/j.1440-1746.2007. 05223.x)

Iorio MV, Visone R, Di Leva G, Donati V, Petrocca F, Casalini P, Taccioli C, Volinia S, Liu CG, Alder H et al. 2007 MicroRNA signatures in human ovarian cancer. Cancer Research 67 8699-8707. (doi:10.1158/00085472.CAN-07-1936)

Lee EJ, Gusev Y, Jiang J, Nuovo GJ, Lerner MR, Frankel WL, Morgan DL, Postier RG, Brackett DJ \& Schmittgen TD 2007 Expression profiling identifies microRNA signature in pancreatic cancer. International Journal of Cancer 120 1046-1054. (doi:10.1002/ijc.22394)

Lee JW, Choi CH, Choi JJ, Park YA, Kim SJ, Hwang SY, Kim WY, Kim TJ, Lee JH, Kim BG et al. 2008 Altered MicroRNA expression in cervical carcinomas. Clinical Cancer Research 14 2535-2542. (doi:10.1158/10780432.CCR-07-1231)

Li W, Xie L, He X, Li J, Tu K, Wei L, Wu J, Guo Y, Ma X, Zhang P et al. 2008 Diagnostic and prognostic implications of microRNAs in human hepatocellular carcinoma. International Journal of Cancer 123 1616-1622. (doi:10.1002/ijc.23693)

Lu J, Getz G, Miska EA, Alvarez-Saavedra E, Lamb J, Peck D, Sweet-Cordero A, Ebert BL, Mak RH, Ferrando AA et al. 2005 MicroRNA expression profiles classify human cancers. Nature 435 834-838. (doi:10.1038/nature03702)

Lui WO, Pourmand N, Patterson BK \& Fire A 2007 Patterns of known and novel small RNAs in human cervical cancer. Cancer Research 67 6031-6043. (doi:10.1158/ 0008-5472.CAN-06-0561)

Meyer-Rochow GY, Smith JM, Richardson A-L, Marsh DJ, Sidhu SB, Robinson BG \& Benn DE 2009 Denaturing high performance liquid chromatography detection of SDHB, SDHD, and VHL germline mutations in pheochromocytoma. Journal of Surgical Research 157 55-62. (doi:10.1016/j.jss.2008.07.043)

Murakami Y, Yasuda T, Saigo K, Urashima T, Toyoda H, Okanoue T \& Shimotohno K 2006 Comprehensive analysis of microRNA expression patterns in hepatocellular carcinoma and non-tumorous tissues. Oncogene $\mathbf{2 5}$ 2537-2545. (doi:10.1038/sj.onc.1209283)
Nam EJ, Yoon H, Kim SW, Kim H, Kim YT, Kim JH, Kim JW \& Kim S 2008 MicroRNA expression profiles in serous ovarian carcinoma. Clinical Cancer Research 14 2690-2695. (doi:10.1158/1078-0432.CCR-07-1731)

Neumann HPH, Bausch B, McWhinney SR, Bender BU, Gimm O, Franke G, Schipper J, Klisch J, Altehoefer C, Zerres K et al. 2002 Germ-line mutations in nonsyndromic pheochromocytoma. New England Journal of Medicine 346 1459-1466. (doi:10.1056/NEJMoa020152)

Pallante P, Visone R, Ferracin M, Ferraro A, Berlingieri MT, Troncone G, Chiappetta G, Liu CG, Santoro M, Negrini M et al. 2006 MicroRNA deregulation in human thyroid papillary carcinomas. Endocrine-Related Cancer $\mathbf{1 3}$ 497-508. (doi:10.1677/erc.1.01209)

Porkka KP, Pfeiffer MJ, Waltering KK, Vessella RL, Tammela TL \& Visakorpi T 2007 MicroRNA expression profiling in prostate cancer. Cancer Research 67 6130-6135. (doi:10.1158/0008-5472.CAN-07-0533)

Ravenel JD, Broman KW, Perlman EJ, Niemitz EL, Jayawardena TM, Bell DW, Haber DA, Uejima H \& Feinberg AP 2001 Loss of imprinting of insulin-like growth factor-II (IGF2) gene in distinguishing specific biologic subtypes of wilms tumor. Journal of the National Cancer Institute 93 1698-1703. (doi:10.1093/jnci/93.22. 1698)

Ritchie ME, Silver J, Oshlack A, Holmes M, Diyagama D, Holloway A \& Smyth GK 2007 A comparison of background correction methods for two-colour microarrays. Bioinformatics 23 2700-2707. (doi:10.1093/ bioinformatics/btm412)

Roccaro AM, Sacco A, Thompson B, Leleu X, Azab AK, Azab F, Runnels J, Jia X, Ngo HT, Melhem MR et al. 2009 MicroRNAs 15 a and 16 regulate tumor proliferation in multiple myeloma. Blood 113 6669-6680. (doi:10. 1182/blood-2009-01-198408)

Roldo C, Missiaglia E, Hagan JP, Falconi M, Capelli P, Bersani S, Calin GA, Volinia S, Liu CG, Scarpa A et al. 2006 MicroRNA expression abnormalities in pancreatic endocrine and acinar tumors are associated with distinctive pathologic features and clinical behavior. Journal of Clinical Oncology 24 4677-4684. (doi:10. 1200/JCO.2005.05.5194)

Schmitt A, Saremaslani P, Schmid S, Rousson V, Montani M, Schmid DM, Heitz PU, Komminoth P \& Perren A 2006 IGFII and MIB1 immunohistochemistry is helpful for the differentiation of benign from malignant adrenocortical tumours. Histopathology 49 298-307. (doi:10.1111/j. 1365-2559.2006.02505.x)

Schultz J, Lorenz P, Gross G, Ibrahim S \& Kunz M 2008 MicroRNA let-7b targets important cell cycle molecules in malignant melanoma cells and interferes with anchorage-independent growth. Cell Research $\mathbf{1 8}$ 549-557. (doi:10.1038/cr.2008.45)

Soon PSH, Gill AJ, Benn DE, Clarkson A, Robinson BG, McDonald KL \& Sidhu SB 2009a Microarray gene expression and immunohistochemistry analyses of 
adrenocortical tumors identify IGF2 and Ki-67 as useful in differentiating carcinomas from adenomas. EndocrineRelated Cancer 16 573-583. (doi:10.1677/ERC-08-0237)

Soon PSH, Tacon LJ, Gill AJ, Bambach CP, Sywak MS, Campbell PR, Yeh MW, Wong SG, Clifton-Bligh RJ, Robinson BG et al. $2009 b$ miR-195 and miR-483-5p identified as predictors of poor prognosis in adrenocortical cancer. Clinical Cancer Research 15 7684-7692. (doi:10.1158/1078-0432.CCR-09-1587)

Strong VE, Kennedy T, Al-Ahmadie H, Tang L, Coleman J, Fong Y, Brennan M \& Ghossein RA 2008 Prognostic indicators of malignancy in adrenal pheochromocytomas: clinical, histopathologic, and cell cycle/apoptosis gene expression analysis. Surgery 143 759-768. (doi:10.1016/ j.surg.2008.02.007)

Szafranska AE, Davison TS, John J, Cannon T, Sipos B, Maghnouj A, Labourier E \& Hahn SA 2007 MicroRNA expression alterations are linked to tumorigenesis and non-neoplastic processes in pancreatic ductal adenocarcinoma. Oncogene 26 4442-4452. (doi:10.1038/sj. onc.1210228)

Takamizawa J, Konishi H, Yanagisawa K, Tomida S, Osada H, Endoh H, Harano T, Yatabe Y, Nagino M, Nimura Y et al. 2004 Reduced expression of the let-7 microRNAs in human lung cancers in association with shortened postoperative survival. Cancer Research 64 3753-3756. (doi:10.1158/0008-5472.CAN-04-0637)

Takeshita F, Patrawala L, Osaki M, Takahashi R-U, Yamamoto Y, Kosaka N, Kawamata M, Kelnar K, Bader AG, Brown D et al. 2010 Systemic delivery of synthetic microRNA-16 inhibits the growth of metastatic prostate tumors via downregulation of multiple cell-cycle genes. Molecular Therapy 18 181-187. (doi:10.1038/mt. 2009.207)

Wang Y, Lee AT, Ma JZ, Wang J, Ren J, Yang Y, Tantoso E, Li KB, Ooi LL, Tan P et al. 2008 Profiling microRNA expression in hepatocellular carcinoma reveals microRNA-224 up-regulation and apoptosis inhibitor-5 as a microRNA-224-specific target. Journal of Biological Chemistry 283 13205-13215. (doi:10.1074/jbc. M707629200)

Weber F, Teresi RE, Broelsch CE, Frilling A \& Eng C 2006 A limited set of human microRNA is deregulated in follicular thyroid carcinoma. Journal of Clinical Endocrinology and Metabolism 91 3584-3591. (doi:10. 1210/jc.2006-0693)

Wong QW, Lung RW, Law PT, Lai PB, Chan KY, To KF \& Wong N 2008 MicroRNA-223 is commonly repressed in hepatocellular carcinoma and potentiates expression of Stathmin1. Gastroenterology 135 257-269. (doi:10.1053/ j.gastro.2008.04.003)

Yanaihara N, Caplen N, Bowman E, Seike M, Kumamoto K, Yi M, Stephens RM, Okamoto A, Yokota J, Tanaka T et al. 2006 Unique microRNA molecular profiles in lung cancer diagnosis and prognosis. Cancer Cell 9 189-198. (doi:10.1016/j.ccr.2006.01.025)

Yang H, Kong W, He L, Zhao JJ, O’Donnell JD, Wang J, Wenham RM, Coppola D, Kruk PA, Nicosia SV et al. 2008 MicroRNA expression profiling in human ovarian cancer: miR-214 induces cell survival and cisplatin resistance by targeting PTEN. Cancer Research 68 425-433. (doi:10.1158/0008-5472.CAN-07-2488) 